Article

\title{
Adsorption Behaviour of Lactic Acid on Granular Activated Carbon and Anionic Resins: Thermodynamics, Isotherms and Kinetic Studies
}

\author{
Nirakar Pradhan ${ }^{1,2,3, *}$, Eldon R. Rene ${ }^{2}$, Piet N. L. Lens ${ }^{2}$, Laura Dipasquale ${ }^{3}$, \\ Giuliana D'Ippolito ${ }^{3}$, Angelo Fontana ${ }^{3}$, Antonio Panico ${ }^{4}$ and Giovanni Esposito ${ }^{1}$ \\ 1 Department of Civil and Mechanical Engineering, University of Cassino and Southern Lazio, \\ Via Di Biasio, 43, 03043 Cassino, Italy; giovanni.esposito@unicas.it \\ 2 UNESCO-IHE Institute for Water Education, Westvest 7, 2611AX Delft, The Netherlands; \\ e.raj@unesco-ihe.org (E.R.R.); p.lens@unesco-ihe.org (P.N.L.L.) \\ 3 Institute of Biomolecular Chemistry, Italian National Council of Research, Via Campi Flegrei 34, \\ 80078 Napoli, Italy; ldipasquale@icb.cnr.it (L.D.); gdippolito@icb.cnr.it (G.D.); afontana@icb.cnr.it (A.F.) \\ 4 Department of Civil Engineering, Telematic University Pegaso, Piazza Trieste E Trento, 48, 80132 Naples, \\ Italy; anpanico@unina.it \\ * Correspondence: nirakar.pradhan@gmail.com; Tel.: +91-79-78799391
}

Academic Editor: S. Kent Hoekman

Received: 14 March 2017; Accepted: 5 May 2017; Published: 10 May 2017

\begin{abstract}
Solid-liquid extraction (adsorption or ion exchange) is a promising approach for the in situ separation of organic acids from fermentation broths. In this study, a diluted concentration of lactic acid ( $<10 \mathrm{~g} / \mathrm{L})$ separation from a model fermentation broth by granular activated carbon (GAC) as well as weak (Reillex ${ }^{\circledR} 425$ or RLX425) and strong (Amberlite ${ }^{\circledR}$ IRA-400 or AMB400) base anion exchange resins under various operating conditions was experimentally investigated. Thermodynamic analysis showed that the best lactic acid adsorption performances were obtained at a $\mathrm{pH}$ below the $p K_{a}$ value of lactic acid (i.e., 3.86) for GAC and RLX425 by physical adsorption mechanism and above the $p K_{a}$ value for the AMB400 resin by an ion exchange mechanism, respectively. The adsorption capacity for GAC (38.2 mg/g) was the highest, followed by AMB400 (31.2 mg/g) and RLX425 (17.2 mg/g). As per the thermodynamic analysis, the lactic acid adsorbed onto GAC and RLX425 through a physical adsorption mechanism, whereas the lactic acid adsorbed onto AMB400 with an ion exchange mechanism. The Langmuir adsorption isotherm model $\left(R^{2}>0.96\right)$ and the pseudo-second order kinetic model $\left(R^{2} \sim 1\right)$ fitted better to the experimental data than the other models tested. Postulating the conditions for the real fermentation broth ( $\mathrm{pH}$ : 5.0-6.5 and temperature: $30-80{ }^{\circ} \mathrm{C}$ ), the resin AMB400 represents an ideal candidate for the extraction of lactic acid during fermentation.
\end{abstract}

Keywords: lactic acid; adsorption; kinetics; isotherms; thermodynamics; ion exchange

\section{Introduction}

Lactic acid (2-hydroxypropionic acid) is an important commercial chemical due to its application in food, medical, pharmaceutical, packaging and textile industries. In the past decades, the demand for lactic acid has been significantly high, especially for its application in biodegradable polymers, i.e., polylactic acid (PLA), which has a potential to replace traditional commodity plastics. PLA-based plastics have some unique features such as high tensile strength, stiffness and resistance to fats and oils compared to traditional plastic materials; however, they require further improvement in some properties and characteristics such as viscosity, thermal stability and production cost [1]. The properties of PLA can be improved by blending with several other synthetic polymers (e.g., 
polystyrene, polyethylene or polypropylene) and biopolymers (e.g., thermoplastic starch, rubbers or poly(3-hydroxybutyrate)) to obtain novel biodegradable materials with lower cost and higher durability compared to the traditional plastic materials [1,2]. However, extraction, purification and continuous supply of lactic acid as raw material from fermentation processes is a major challenge because of its highly hydrophilic structure and the lack of efficient low cost purification techniques [3].

Lactic acid has a chiral carbon atom and exists in two isomeric forms, i.e., L-(+) and D-(-). Industrially preferred L-(+)lactic acid can be manufactured either by the chemical synthesis of acetaldehyde or by fermentation processes, where the latter accounts for $\sim 90 \%$ of the global lactic acid production [4]. Traditionally, lactic acid is produced by homolactic fermentation processes using pure cultures of lactic acid bacteria belonging to the genus Lactobacillus [5]. Recently, a heterolactic fermentation process with a new metabolic pathway named capnophilic $\left(\mathrm{CO}_{2}\right.$-led) lactic fermentation (CLF) was found to be present in the hyperthermophilic marine bacterium Thermotoga neapolitana [6]. Under CLF conditions, both hydrogen and lactic acid are synthesized simultaneously unlike in the classic dark fermentation processes [6-9]. T. neapolitana fermentation takes place on a wide range of carbohydrate-rich substrates at $80^{\circ} \mathrm{C}(353.15 \mathrm{~K})$ and $\mathrm{pH}$ 6.5. However, the lactic acid concentration in the T. neapolitana fermentation broth is in the lower range $(2-10 \mathrm{~g} / \mathrm{L})$ compared to lactic acid fermentation (50-150 $\mathrm{g} / \mathrm{L}$ lactic acid) by homolactic fermentation processes $[10,11]$.

Several downstream processing techniques have been used to recover lactic acid from the fermentation broth, e.g., calcium lactate crystallization, ion-exchange, adsorption, esterificationdistillation/hydrolysis, membrane extraction and electro-dialysis [12-15]. Among these techniques, adsorption by activated carbon and anionic resins are suitable for fermentation broths with low concentrations of lactic acid, especially from heterolactic fermentation [16,17]. A wide range of anionic resins are commercially available with various functional groups and support matrices, which makes the adsorption process more flexible under various operating conditions. The adsorption capacity and efficiency are influenced by various factors such as the properties of the adsorbent (porosity, surface area, particle size and functional group), the adsorbate (polarity, $p K_{a}$, molecular weight, structure and solute concentration) and the operating conditions (contact time, $\mathrm{pH}$, temperature and mixing speed) [18].

Several anionic adsorbents such as Amberlite ${ }^{\circledR}$ IRA-67 (Sigma Aldrich SRL, Milan, Italy) [18], IRA-92 [19], IRA-400 [20], IRA-425 [21] and a non-polar adsorbent like activated carbon [18,22] have been studied for lactic or organic acids adsorption from a fermentation broth at room temperature. Most of the anionic resins are non-toxic to microorganisms and can thus be used directly in the fermenter [23]. Activated carbon has a wider application in the field of water and wastewater treatment due to its highly porous structure with a large surface area $\left(\sim 1100 \mathrm{~m}^{2} / \mathrm{g}\right)$. Granular activated carbon (GAC) also shows specific affinity towards organic acids like acetic, lactic and butyric acid because of its non-polar nature at different $\mathrm{pH}$ conditions [22,24].

In this paper, the effects of contact time, initial $\mathrm{pH}$, adsorbent dose lactic acid concentration and temperature on the adsorption of lactic acid from a model fermentation broth by GAC, as well as weakly-basic (Reillex ${ }^{\circledR} 425$, Sigma Aldrich SRL, Milan, Italy) and strongly-basic (Amberlite ${ }^{\circledR}$ IRA-400) anion exchange resins were investigated in batch equilibrium studies. For the first time, the thermodynamic characteristics of lactic acid adsorption onto adsorbents were investigated systematically as a function of temperature. To understand the adsorbate-adsorbent mechanism and kinetics, the lactic acid adsorption data were analyzed using suitable adsorption isotherms and kinetic models. These results enable for the extraction of lactic acid during hyperthermophilic T. neapolitana or similar dark fermentation processes. 


\section{Materials and Methods}

\subsection{Adsorbents}

Three types of adsorbents were studied for the extraction of lactic acid: (i) Norit ${ }^{\circledR}$ GAC 1240EN with a particle size of 10-40 mesh and a moisture content $<5 \%$ (source: www.cabotcorp.com); (ii) Reillex ${ }^{\circledR} 425$ (Poly(4-viniylpyridine)), hereafter referred as RLX425, a weakly basic anion exchange resin cross-linked with $25 \%$ divinylbenzene, with pyridine as the functional group, a particle size of 20-50 mesh and a moisture content in the range of 50-75\% (source: www.sigmaaldrich.com) and (iii) Amberlite ${ }^{\circledR}$ IRA-400 $\left(\mathrm{Cl}^{-}\right)$, hereafter referred as AMB400, a strongly basic anion exchange resin cross-linked with $8 \%$ styrene/divinylbenzene (gel), with quaternary ammonium as the functional group, a particle size of 20-25 mesh and a moisture content in the range of 40-47\% (source: www.sigmaaldrich.com). The analytical grade anionic resins were purchased from Sigma-Aldrich (Milan, Italy) and used without any pre-treatment.

\subsection{Batch Adsorption Tests}

The batch equilibrium experiments were conducted in a temperature-controlled $\left(30-80{ }^{\circ} \mathrm{C}\right.$ or 303.15-353.15 K) environment, either on an orbital shaker (INNOVA 2100, New Brunswick Scientific, Bordentown, NJ, USA) at a speed of $180 \mathrm{rpm}$ or a shaking thermostatic water bath (GFL1083, GFL, Burgwedel, Germany) as per Dethe et al. [13]. The model fermentation broth was prepared from an analytical grade 88\% L-(+)lactic acid stock solution (Sigma-aldrich Cheme BV, Zwijndrecht, The Netherlands) and demineralized water as described by Moldes et al. [17]. The initial pH (2.0-6.5) of the bulk solution was adjusted by either adding $6.0 \mathrm{M} \mathrm{NaOH}$ or $6.0 \mathrm{M} \mathrm{HCl}$. $25.0 \mathrm{~mL}$ serum bottles with screw cap containing $5.0 \mathrm{~mL}$ of model fermentation broth ( $4.5 \mathrm{~g} / \mathrm{L}$ lactic acid) and $0.5 \mathrm{~g}$ adsorbent (or $10 \% w / v$ ) were used for all the batch adsorption studies unless stated otherwise. The adsorbent GAC and RLX425 were studied at pH 2.0, whereas AMB400 was studied at pH 5.0 based on pre-screening experiments and a literature survey [13]. The model fermentation broth was allowed to equilibrate for $4 \mathrm{~h}$ on an orbital shaker and maintained at $303.15 \mathrm{~K}$. All the batch adsorption experiments were performed in duplicate by employing individual serum bottles for each data point.

\subsection{Experimental Design}

The lactic acid adsorption study comprised 6 different series of experiments, investigating the effect of (i) contact time; (ii) initial pH; (iii) adsorbent dose; (iv) initial lactic acid concentration; (v) temperature and (vi) batch kinetic studies on the adsorption process. The effect of contact time was tested for a period of $24 \mathrm{~h}$ by using a model fermentation broth without initial $\mathrm{pH}(\sim 2.35)$ corrections with samples withdrawn at different time intervals $(0,2,4,6,8$ and $24 \mathrm{~h})$. The adsorption capacity and efficiency (i.e., \% lactic acid adsorbed onto the adsorbent) under equilibrium conditions were calculated using Equations (1) and (2), respectively:

$$
\begin{aligned}
q_{e} & =\frac{\left(C_{0}-C_{e}\right) \times V}{m} \\
E & =\frac{C_{0}-C_{e}}{C_{0}} \times 100
\end{aligned}
$$

where $q_{e}=$ amount of adsorbate in the adsorbent at equilibrium $(\mathrm{mg} / \mathrm{g}), E=$ lactic acid recovery efficiency $(\%), C_{0}=$ initial concentration of lactic acid $(\mathrm{mg} / \mathrm{L}), C_{e}=$ equilibrium concentration of lactic acid in the solution $(\mathrm{mg} / \mathrm{L}), V=$ volume of the solution $(\mathrm{L})$ and $m=$ mass of the adsorbent $(\mathrm{g})$. 
The effect of the initial $\mathrm{pH}$ was tested at 5 different initial $\mathrm{pH}(2.0,2.35,3.86,5.0$ and 6.5) conditions, both above and below the $p K_{a}$ (3.86) value of lactic acid. The degree of ionization of lactic acid depends on the $\mathrm{pH}$ and can be calculated using Equation (3):

$$
\% \text { Ionized }=\frac{100}{1+\exp \left(p K_{a}-p H\right)}
$$

The effect of the adsorbent dose was tested to determine the appropriate adsorbent dose $(w / v$ basis) by varying the dose from $5 \%$ to $30 \%(w / v)$ with an increment of $5 \%$ in each step. The effect of the lactic acid concentration was tested for 9 different lactic acid concentrations, varying between 1.5 and $36.3 \mathrm{~g} / \mathrm{L}$. This range was particularly selected to represent the lactic acid production from various homolactic or heterolactic fermentation processes with low concentration of lactic acid in the fermentation broth $[8,18]$.

Lactic acid adsorption was investigated at various temperatures (303.15-353.15 K). The thermodynamic parameters including Gibbs free energy $\left(\Delta G^{0}\right)$, enthalpy $\left(\Delta H^{0}\right)$ and entropy $\left(\Delta S^{0}\right)$ are the indicators of the adsorption process and their values indicate the spontaneity and favorability of the process [25,26]. The $\Delta G^{0}$ can be calculated from Equation (4), whereas $\Delta H^{0}$ and $\Delta S^{0}$ can be calculated by using the Van't Hoff equation (Equation (5)), i.e., from the slope and intercept of the linear plot of $\ln K_{L}$ versus 1/T:

$$
\begin{gathered}
\Delta G^{0}=-R T \ln K_{L} \\
\ln K_{L}=\frac{-\Delta G^{0}}{R T}=-\frac{\Delta H^{0}}{R T}+\frac{\Delta S^{0}}{R}
\end{gathered}
$$

where $K_{L}=$ Langmuir isotherm constant $(\mathrm{L} / \mathrm{mol}), R=$ universal gas constant $(8.31 \mathrm{~J} /(\mathrm{mol} \mathrm{K}))$, $T=$ temperature (Kelvin), $\Delta G^{0}=$ Gibbs free energy $(\mathrm{kJ} / \mathrm{mol}), \Delta H^{0}=$ enthalpy $(\mathrm{kJ} / \mathrm{mol})$ and $\Delta S^{0}=$ entropy $(\mathrm{kJ} /(\mathrm{mol} \mathrm{K}))$.

\subsection{Analytical Methods}

The initial and final concentrations of lactic acid were measured through an ion chromatography technique by ICS-1100 (Dionex, Thermo Fisher Scientific Inc., Waltham, MA, USA) using an IonPac ${ }^{\circledR}$ AS4A-SC (solvent compatible, Dionex, Thermo Fisher Scientific Inc., Waltham, MA, USA) carbonate-selective anion exchange analytical column [27]. The mobile phase had $1.7 \mathrm{mM} \mathrm{NaHCO}$ and $1.8 \mathrm{mM} \mathrm{Na}_{2} \mathrm{CO}_{3}$ with a flow rate of $0.5 \mathrm{~mL} / \mathrm{min}$. Before analysis, the $\mathrm{pH}$ of all the samples was adjusted in the range of 5.0 to 8.0 by using either $6.0 \mathrm{M} \mathrm{HCl}$ or $6.0 \mathrm{M} \mathrm{NaOH}$.

\subsection{Lactic Acid Adsorption Isotherms}

The batch equilibrium results of different initial lactic acid concentration experiments at $303.15 \mathrm{~K}$ were used for the isotherm study. In this study, we chose three commonly used isotherm models (i.e., Langmuir (Equation (I)), Freundlich (Equation (II)) and Temkin (Equation (III))) to describe the lactic acid adsorption process $[25,28]$. The linear and non-linear forms of the isotherm model equations are presented in Table $1[28,29]$.

The Langmuir adsorption isotherm model assumes homogeneous and monolayer adsorption with no lateral interaction or steric hindrances between the adsorbate molecules [29]. The nature of adsorption in the Langmuir adsorption isotherm model is represented by a dimensionless constant known as the separation factor $\left(R_{L}\right), R_{L}=1 /\left(1+\left(K_{L} \times C_{0}\right)\right)$, where $K_{L}=$ Langmuir isotherm constant $(\mathrm{L} / \mathrm{mg}), C_{0}=$ initial concentration of lactic acid $(\mathrm{mg} / \mathrm{L}), R_{L}>1$ (unfavorable), $R_{L}=1$ (linear), $R_{L}=0$ (irreversible) and $0<R_{L}<1$ (favorable) [30].

On the other hand, the Freundlich isotherm model describes a non-ideal and reversible adsorption process, which is applied to explain the multilayer adsorption onto a heterogeneous adsorbent surface [31]. The Temkin isotherm model assumes that the heat of adsorption of all the molecules in the layer would decrease linearly rather than logarithmically [29]. 
Table 1. List of non-linear and linear forms of adsorption isotherm model equations.

\begin{tabular}{c|c|c|c|c}
\hline Isotherms & Non-Linear Form & Linear Form & Plot & Equation \\
\hline Langmuir & $q_{e}=\frac{q_{m} K_{L} C_{e}}{1+K_{L} C_{e}}$ & $\frac{1}{q_{e}}=\frac{1}{q_{m}}+\frac{1}{K_{L} q_{m} C_{e}}$ & $\frac{1}{q_{e}}$ vs. $\frac{1}{C_{e}}$ & (I) \\
\hline Freundlich & $q_{e}=K_{F} C_{e}^{\frac{1}{n}}$ & $\log q_{e}=\log K_{F}+\frac{1}{n} \log C_{e}$ & $\log q_{e}$ vs. $\log C_{e}$ & (II) \\
\hline Temkin & $q_{e}=\frac{R T}{K_{T}} \ln A_{T} C_{e}$ & $q_{e}=\frac{R T}{K_{T}} \ln A_{T}+\frac{R T}{K_{T}} \ln C_{e}$ & $q_{e}$ vs. $\ln C_{e}$ & (III) \\
\hline
\end{tabular}

Notes: $q_{e}=$ amount of adsorbate in the adsorbent at equilibrium $(\mathrm{mg} / \mathrm{g}), C_{e}=$ equilibrium concentration of lactic acid in the solution $(\mathrm{mg} / \mathrm{L}), q_{m}=$ maximum monolayer coverage capacities $(\mathrm{mg} / \mathrm{g}), K_{L}=$ Langmuir isotherm constant $(\mathrm{L} / \mathrm{mg}), n=$ adsorption intensity, $K_{F}=$ Freundlich isotherm constant $(\mathrm{mg} / \mathrm{g})(\mathrm{L} / \mathrm{g})^{n}, A_{T}=$ Temkin isotherm equilibrium binding constant $(\mathrm{L} / \mathrm{g}), K_{T}=$ Temkin isotherm constant, $R=$ universal gas constant $(8.314 \mathrm{~J} /(\mathrm{mol} \mathrm{K}))$ and $T=$ temperature (K); Source: Modified from Pezoti et al. [28], Foo and Hameed [29] and Chen [31].

\subsection{Lactic Acid Adsorption Kinetics}

Lactic acid adsorption kinetics were studied for a period of $8 \mathrm{~h}$ in order to understand the adsorption mechanism and the binding properties of lactic acid onto the adsorbents. The samples were periodically collected from the serum bottles and analyzed for residual lactic acid concentrations. The kinetic models of pseudo-first order (Equation (A)), pseudo-second order (Equation (B)) and Elovich (Equation (C)) were investigated in order to describe the adsorption dynamics of lactic acid onto the GAC, RLX425 and AMB400 [28]. The differential and linear forms of the adsorption kinetic model equations are shown in Table $2[32,33]$.

Table 2. List of differential and linear forms of adsorption kinetic model equations.

\begin{tabular}{c|c|c|c|c}
\hline Kinetic Model & Differential Form & Linear Form & Plot & Equation \\
\hline $\begin{array}{c}\text { Pseudo-First } \\
\text { Order }\end{array}$ & $\frac{d q_{t}}{d t}=K_{1}\left(q_{e}-q_{t}\right)$ & $\log \left(q_{e}-q_{t}\right)=\log q_{e}-\left(\frac{K_{1}}{2.303}\right) t$ & $\log \left(q_{e}-q_{t}\right)$ vs. $t$ & (A) \\
\hline $\begin{array}{c}\text { Pseudo-Second } \\
\text { Order }\end{array}$ & $\frac{d q_{t}}{d t}=K_{2}\left(q_{e}-q_{t}\right)^{2}$ & $\frac{t}{q_{t}}=\frac{1}{K_{2} q_{e}^{2}}+\frac{1}{q_{e}} t=\frac{1}{h_{0}}+\frac{1}{q_{e}} t$ & $\frac{t}{q_{t}}$ vs. $t$ & (B) \\
\hline Elovich & $\frac{d q_{t}}{d t}=\alpha e^{-\beta q_{t}}$ & $q_{t}=\beta \ln \alpha \beta+\ln t$ & $q_{t}$ vs. $\ln t$ & (C) \\
\hline
\end{tabular}

Notes: $K_{1}=$ pseudo-first order rate constant $\left(\mathrm{min}^{-1}\right), q_{e}=$ amount of adsorbate in the adsorbent at equilibrium $(\mathrm{mg} / \mathrm{g}), t=$ time $(\mathrm{min}), q_{t}=$ adsorption at any given point of time $(\mathrm{mg} / \mathrm{g}), K_{2}=$ pseudo-second order rate constant $(\mathrm{mg} / \mathrm{g} / \mathrm{min}), h_{0}=$ initial adsorption rate $\left(\mathrm{min}^{-1}\right), \beta=$ desorption constant $(\mathrm{g} / \mathrm{mg})$ and $\alpha=$ initial adsorption rate (mg/g/min).

\section{Results}

\subsection{Effect of Contact Time, pH, Adsorbent Dose and Lactic Acid Concentration on Lactic Acid Adsorption}

The contact time experiments showed that the adsorption reached its equilibrium between 2 and $6 \mathrm{~h}$ with lactic acid adsorbed onto GAC ( $29 \mathrm{mg}$ lactic acid/g adsorbent), RLX425 (18 mg lactic acid/g adsorbent) and AMB400 (10 mg lactic acid/g adsorbent) from an initial concentration of $4.5 \mathrm{~g}$ lactic acid/L (Figure 1a). From this batch experiment, a contact time of $4 \mathrm{~h}$ was selected for the subsequent experiments.

The experimental results confirmed that both GAC and RLX425 show selectivity at a pH (2.0) below $p K_{a}$ (3.86) value of the lactic acid and AMB400 at a $\mathrm{pH}(5.0)$ above the $p K_{a}$ value (Figure 1b). The adsorption of lactic acid depends on the degree of ionization of lactic acid in the bulk solution, which was calculated from the relation between the $p K_{a}$ value and the $\mathrm{pH}$ of the solution. The degree of ionization was found to be $13.5 \%, 18.1 \%, 24.2 \%$ and $6.7 \%$ at $\mathrm{pH} 2.0,2.35,5.0$ and 6.5 , respectively.

Figure 1c shows the lactic acid recovery efficiency with different adsorbent dose in the range of $5 \%$ to $30 \%(w / v)$. The increase in GAC dose from $5 \%$ to $30 \%(w / v)$ increased the lactic acid recovery efficiency from $79.0( \pm 0.5) \%$ to $90.1( \pm 0.3) \%$. Similarly, for RLX425, the increase of adsorbent dose from $5 \%$ to $30 \%(w / v)$ increased the lactic acid recovery efficiency from $27.8( \pm 0.7) \%$ to $62.9( \pm 3.9) \%$. Concerning AMB400, the increase of adsorbent doses from $5 \%$ to $30 \%(w / v)$ increased the lactic 
acid recovery efficiency from $41.7( \pm 1.4) \%$ to $73.1( \pm 1.1) \%$. The experimental results with different adsorbent dose showed that $10-15 \%(w / v)$ adsorbent dose has a good lactic acid recovery (\%), and thus, $10 \%(w / v)$ adsorbent dose was selected for all the batch adsorption experiments.

The binding capacity of lactic acid was studied by varying the initial lactic acid concentration in the range of 1.5 to $36.3 \mathrm{~g} / \mathrm{L}$ as shown in Figure $1 \mathrm{~d}$. The lactic acid recovery efficiency decreased from $83.2( \pm 0.9) \%$ to $38.2( \pm 0.2) \%$ for GAC when the lactic acid concentration increased from $1.5 \mathrm{~g} / \mathrm{L}$ to $36.3 \mathrm{~g} / \mathrm{L}$. However, the adsorption capacity $\left(q_{e}\right)$ with GAC increased sharply from $12 \mathrm{mg}$ lactic acid/g adsorbent (at $1.5 \mathrm{~g} / \mathrm{L}$ lactic acid) to $162 \mathrm{mg}$ lactic acid/g adsorbent (at $36.3 \mathrm{~g} / \mathrm{L}$ lactic acid). Similarly, for RLX425, the lactic acid recovery efficiency decreased from $41.9( \pm 6.6) \%$ (at $1.5 \mathrm{~g} / \mathrm{L}$ lactic acid) to $19.1( \pm 0.5) \%$ (at $36.3 \mathrm{~g} / \mathrm{L}$ lactic acid) with a maximum $q_{e}$ value of $79 \mathrm{mg}$ lactic acid/g adsorbent (at $36.3 \mathrm{~g} / \mathrm{L}$ lactic acid). The recovery efficiency for AMB400 decreased from $58.8( \pm 2.6) \%$ to 20.2 $( \pm 0.1) \%$, with an increase in the lactic acid concentration from $1.5 \mathrm{~g} / \mathrm{L}$ to $36.3 \mathrm{~g} / \mathrm{L}$ and the maximum $q_{e}$ value was found to be $73 \mathrm{mg}$ lactic acid/g adsorbent at a lactic acid concentration of $36.3 \mathrm{~g} / \mathrm{L}$.

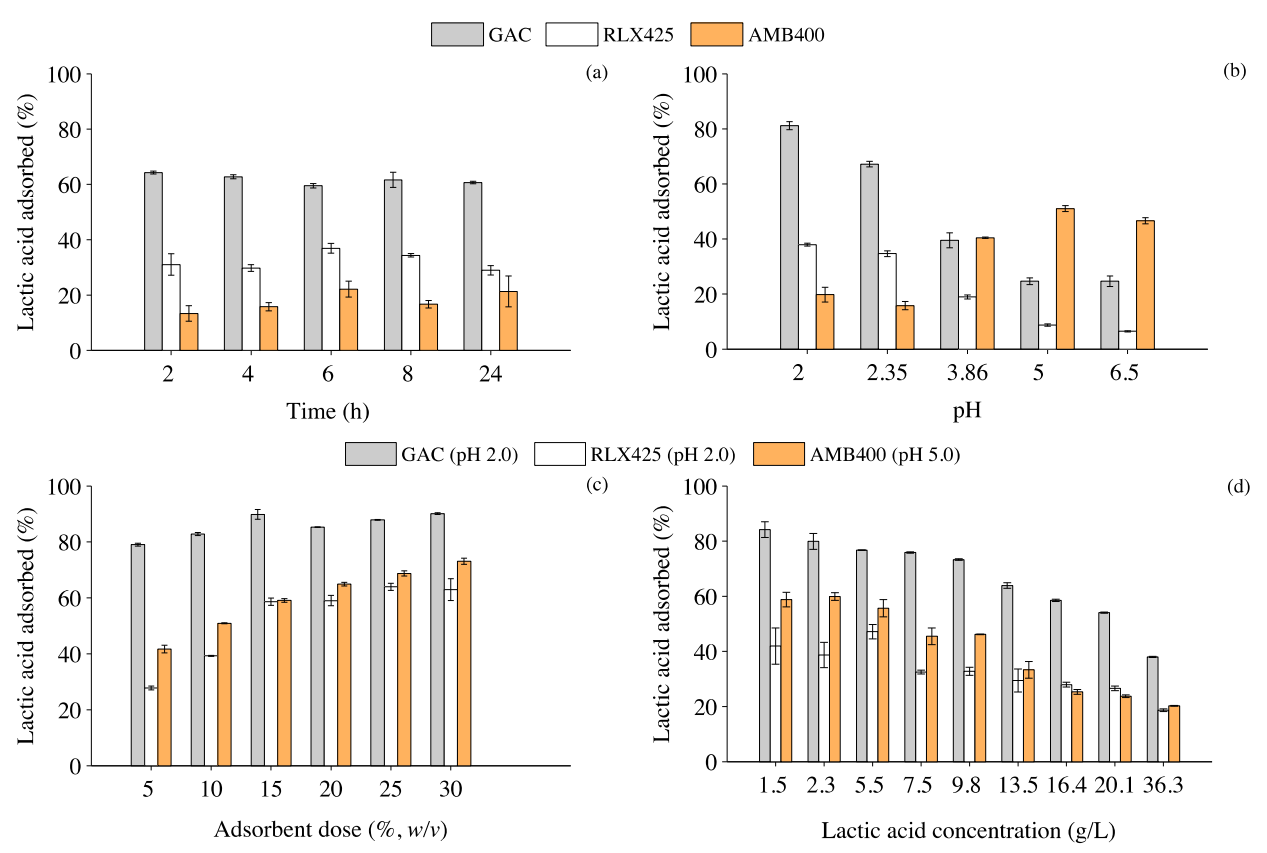

Figure 1. Effect of lactic acid adsorption onto GAC, RLX425 and AMB400 at 303.15 K. (a) Contact time (0-24 h) with $4.5 \mathrm{~g} / \mathrm{L}$ of lactic acid in the bulk solution without initial $\mathrm{pH}$ correction and an adsorbent dose of $10 \%(w / v)$; (b) different initial $\mathrm{pH}(2.0-6.5)$ with $4.5 \mathrm{~g} / \mathrm{L}$ of lactic acid in the bulk solution and an adsorbent dose of $10 \%(w / v)$; (c) various adsorbent doses (5-30\%) with $4.5 \mathrm{~g} / \mathrm{L}$ of lactic acid in the bulk solution accompanied by initial $\mathrm{pH}$ corrections and (d) different initial lactic acid concentrations (1.5-36.3 g/L) accompanied by initial $\mathrm{pH}$ correction with an adsorbent dose of $10 \%(w / v)$.

\subsection{Thermodynamic Analysis and Effect of Temperature on Lactic acid Adsorption}

The effect of temperature ( 303.15 to $353.15 \mathrm{~K}$ ) on lactic acid adsorption onto the adsorbents is shown in Figure 2a. The temperature was raised to $353.15 \mathrm{~K}$ to test the effectiveness of the absorbents to adsorb lactic acid from a model fermentation broth representing T. neapolitana fermentation, which operates at $353.15 \mathrm{~K}$ (or $80^{\circ} \mathrm{C}$ ). Both GAC and RLX425 exhibited a decrease in $q_{e}$ and recovery efficiency values for temperatures higher than $313.15 \mathrm{~K}$. Increasing the temperature from 303.15 to $353.15 \mathrm{~K}$ decreased the adsorption capacity of GAC and RLX 425 by $~ 13 \%$ and 50\%, respectively. When the temperature exceeded $313.15 \mathrm{~K}$, desorption of lactic acid was observed for both GAC and RLX425. In contrast, the $q_{e}(24 \mathrm{mg}$ lactic acid/g adsorbent) and recovery efficiency $(\sim 51 \%)$ of AMB400 remained nearly constant throughout the tested temperature range $(303.15-353.15 \mathrm{~K})$, thus making the resin more suitable for in situ applications than GAC and RLX425. 
The thermodynamic parameters for lactic acid adsorption were calculated from Figure $2 b$ by using the Van't Hoff equation. The thermodynamic model assumed (i) fluid density and viscosity are constant and (ii) isothermal operation during the adsorption of lactic acid. The corresponding $\Delta G^{0}$ values are shown in Table 3. The results clearly show that the adsorption process by both GAC and RLX425 is exothermic (i.e., $\Delta H^{0}<0$ ) and adsorption by AMB400 is endothermic (i.e., $\Delta H^{0}>0$ ). The $\Delta G^{0}<0$ for all the tested adsorbents indicate that the adsorption process is favorable (GAC > AMB400 > RLX425) and spontaneous.
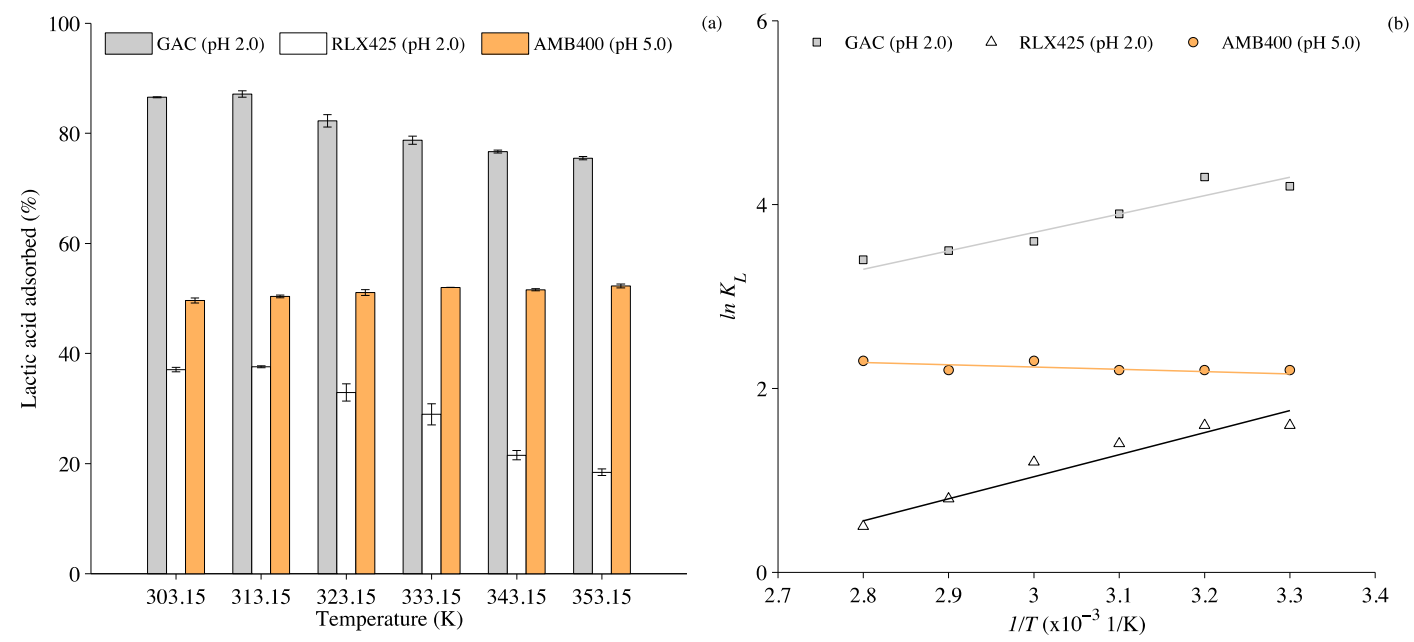

Figure 2. (a) Effect of temperature (303.15-353.15 K) on the adsorption capacities of the adsorbents with $4.5 \mathrm{~g} / \mathrm{L}$ of lactic acid in the bulk solution accompanied by initial $\mathrm{pH}$ corrections and $10 \%(w / v)$ adsorbent dose and (b) plot of $\ln K_{L}$ versus $1 / T$ at a lactic acid concentration of $4.5 \mathrm{~g} / \mathrm{L}$ in the temperature range of 303.15-353.15 K.

Table 3. Gibbs free energy for adsorption of lactic acid onto GAC, RLX425 and AMB400 at temperature ranges from 303.15 to $353.15 \mathrm{~K}\left(\Delta H^{0}=-16.7 \mathrm{~kJ} / \mathrm{mol}\right.$ and $\Delta S^{0}=-0.02 \mathrm{~kJ} /(\mathrm{mol} \mathrm{K})$ for GAC; $\Delta H^{0}=-19.9 \mathrm{~kJ} / \mathrm{mol}$ and $\Delta S^{0}=-0.05 \mathrm{~kJ} /(\mathrm{mol} \mathrm{K})$ for RLX $425 ; \Delta H^{0}=2.0 \mathrm{~kJ} / \mathrm{mol}$ and $\Delta S^{0}=0.02 \mathrm{~kJ} /(\mathrm{mol} \mathrm{K})$ for AMB400).

\begin{tabular}{cccc}
\hline Adsorbents & GAC & RLX425 & AMB400 \\
\hline Temperature (K) & $\boldsymbol{\Delta} \boldsymbol{G}^{\mathbf{0}} \mathbf{( \mathbf { k J } / \mathbf { m o l } )}$ & $\boldsymbol{\Delta} \boldsymbol{G}^{\mathbf{0}} \mathbf{( \mathbf { k J } / \mathbf { m o l } )}$ & $\boldsymbol{\Delta G ^ { \mathbf { 0 } } \mathbf { ( k J } / \mathbf { m o l } )}$ \\
\hline 303.15 & -10.9 & -4.5 & -5.5 \\
\hline 313.15 & -10.7 & -4.0 & -5.8 \\
\hline 323.15 & -10.5 & -3.5 & -6.0 \\
\hline 333.15 & -10.4 & -3.0 & -6.3 \\
\hline 343.15 & -10.2 & -2.4 & -6.5 \\
\hline 353.15 & -9.9 & -1.9 & -6.8 \\
\hline
\end{tabular}

\subsection{Lactic Acid Adsorption Isotherms}

Figure 3 shows the linearized plots for three different adsorption isotherms (Langmuir, Freundlich and Temkin) of lactic acid adsorption at $303.15 \mathrm{~K}$. Table 4 presents the isotherm parameters and regression coefficients for all the isotherm plots. Figure 3 a shows the linear fit $\left(1 / q_{e}\right.$ versus $\left.1 / C_{e}\right)$ of the Langmuir isotherm model. The maximum monolayer adsorption capacity $\left(q_{m}\right)$ value was found to be the highest for GAC (126.6 mg lactic acid/g adsorbent), followed by RLX425 (108.7 mg lactic acid/g adsorbent) and AMB400 (63.5 mg lactic acid/g adsorbent). In addition, the separation factor $\left(R_{L}\right)$ values, calculated to be in the range of 0.05-0.6 for GAC, 0.2-0.9 for RLX425 and 0.2-0.8 for AMB400, 
indicate a favorable adsorption process. A good agreement $\left(R^{2}>0.96\right)$ was observed between the experimental data and the Langmuir isotherm model.

Figure $3 \mathrm{~b}$ shows the plot between $\log q_{e}$ versus $\log C_{e}$ for the Freundlich isotherm model. The adsorption intensity ( $n$ ) was the highest for AMB400, followed by GAC and RLX425 (Table 4). The slope $(1 / n)$ in Figure $3 b$ ranges between 0 and 1 and is a measure of surface heterogeneity, where the adsorption becomes more heterogeneous as the $1 / n$ value approaches 0 [29]. Table 4 shows $n>1$ for all the adsorbents investigated, indicating a nonlinearity due to adsorption site heterogeneity. The Temkin isotherm model shows the adsorption potential of the adsorbent towards the adsorbate. The Temkin isotherm parameters such as $A_{T}$ and $K_{T}$ were calculated from the linear plots of $q_{e}$ versus $\ln C_{e}$ as shown in Figure 3c. The Temkin isotherm model showed a reasonably good fitting between the experimental results of lactic acid adsorption and the model prediction for all the adsorbents investigated.
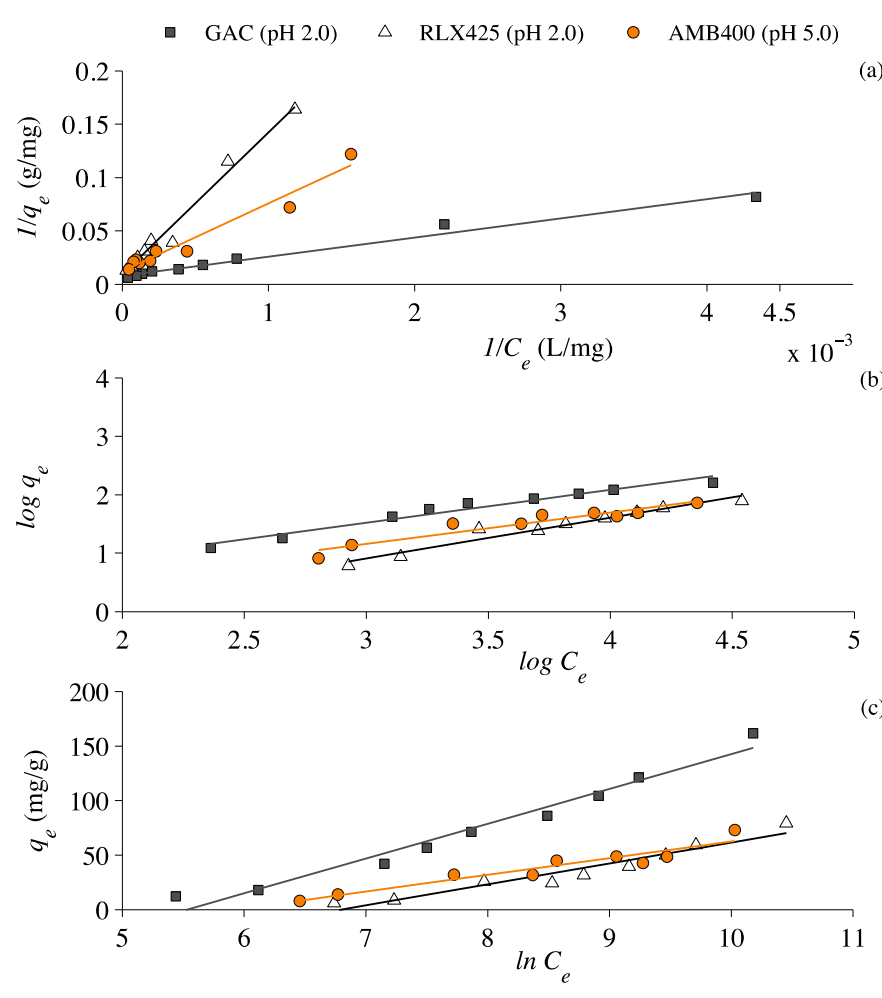

Figure 3. Linear fits of the (a) Langmuir, (b) Freundlich and (c) Temkin isotherm models for GAC and RLX425 at initial pH 2.0 and AMB400 at initial pH 5.0 with $4.5 \mathrm{~g} / \mathrm{L}$ of lactic acid in the bulk solution at $303.15 \mathrm{~K}$ and an adsorbent dose of $10 \%(w / v)$.

Table 4. The Langmuir, Freundlich and Temkin isotherm model parameters obtained from the linear fitting for the three adsorbents (GAC, RLX425 and AMB400).

\begin{tabular}{cccccc}
\hline Isotherms & Coefficients & Units & GAC & RLX425 & AMB400 \\
\hline \multirow{3}{*}{ Langmuir } & $q_{m}$ & $\mathrm{mg} / \mathrm{g}$ & 126.6 & 108.7 & 63.5 \\
& $K_{L}$ & $\mathrm{~L} / \mathrm{mg}$ & $4.4 \times 10^{-4}$ & $6.9 \times 10^{-5}$ & $1.9 \times 10^{-4}$ \\
& $R^{2}$ & - & 0.98 & 0.98 & 0.96 \\
\hline \multirow{3}{*}{ Freundlich } & $n$ & - & 1.8 & 1.4 & 1.9 \\
& $K_{F}$ & $\mathrm{mg} / \mathrm{g}(\mathrm{L} / \mathrm{g})^{n}$ & 1.2 & 3.3 & 1.6 \\
& $R^{2}$ & - & 0.96 & 0.95 & 0.90 \\
\hline \multirow{3}{*}{ Temkin } & $A_{T}$ & $\mathrm{~L} / \mathrm{g}$ & 251.7 & 887.6 & 371.3 \\
& $K_{T}$ & - & 31.9 & 19.2 & 15.3 \\
& $R^{2}$ & - & 0.97 & 0.93 & 0.91 \\
\hline
\end{tabular}




\subsection{Lactic Acid Adsorption Kinetics}

Among the adsorption kinetic models (i.e., pseudo-first order, pseudo-second order and Elovich) investigated, only the pseudo-second order kinetic model followed the experimental results. Figure 4 shows the pseudo-first order, pseudo-second order and Elovich kinetic model plots for lactic acid adsorption onto GAC, RLX425 and AMB400, respectively. The pseudo-first order and Elovich kinetic model showed poor fitting between the experimental and model predicted results (data not shown), and hence these models failed to explain the experimental results.

The straight-line plot (Figure $4 \mathrm{~b}$ ) between $t / q_{t}$ versus $t$ was used to calculate the pseudo-second order kinetic constants, namely $q_{e}$ and $K_{2}$ as shown in Table 5 . Figure $4 \mathrm{~b}$ shows a good correlation $\left(R^{2} \sim 1\right)$ between the experimental data and the model predictions for the three adsorbents tested. The initial adsorption rate $\left(h_{0}\right)$ was the highest for AMB400 $\left(142.9 \mathrm{~min}^{-1}\right)$, followed by GAC $\left(31.5 \mathrm{~min}^{-1}\right)$ and RLX425 (13.6 $\mathrm{min}^{-1}$ ). The $q_{e}$ value was the highest for GAC (38.2 $\mathrm{mg}$ lactic acid/g adsorbent), followed by AMB400 (31.2 mg lactic acid/g adsorbent) and RLX425 (17.2 mg lactic acid/g adsorbent).
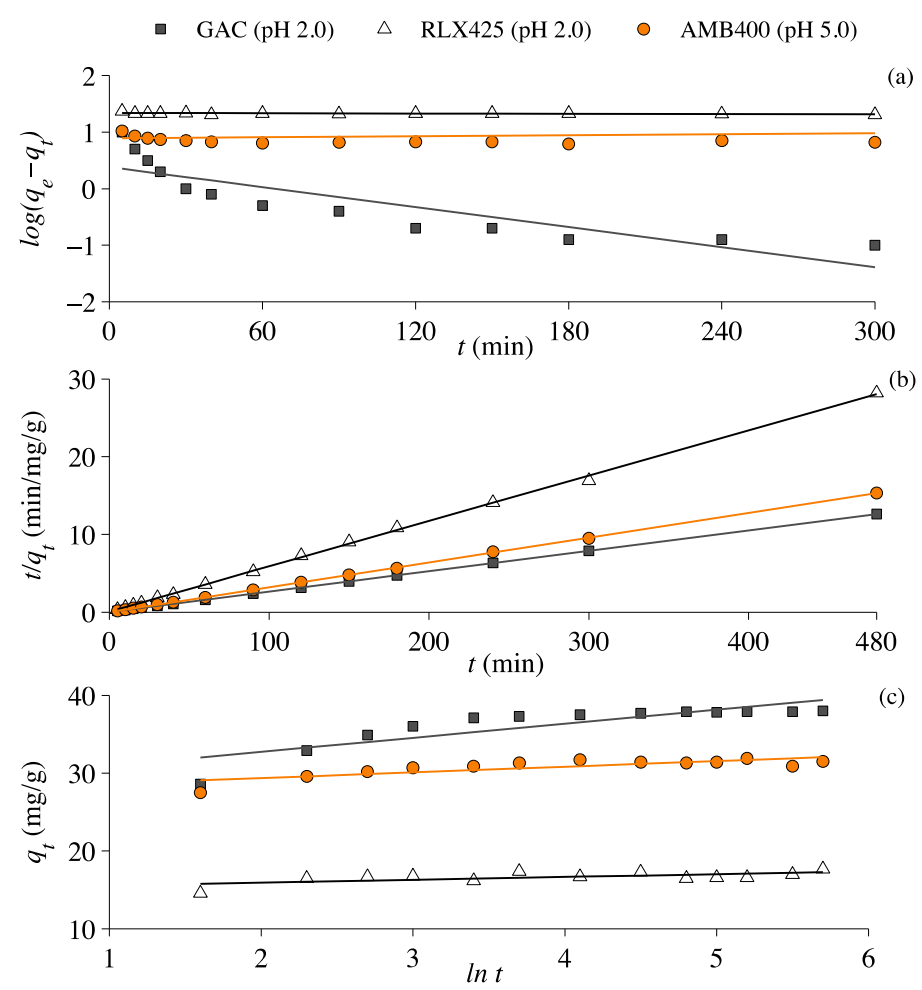

Figure 4. Adsorption kinetics of lactic acid by the three adsorbents GAC, RLX425 and AMB400 at 303.15 K. (a) Pseudo-first order; (b) pseudo-second order and (c) Elovich kinetic models at an initial lactic acid concentration of $4.5 \mathrm{~g} / \mathrm{L}$ and an adsorbent dose of $10 \%(w / v)$.

Table 5. Pseudo-second order model kinetic parameters for the three adsorbents (GAC, RLX452 and $\mathrm{AMB} 400)$ at $303.15 \mathrm{~K}$ and with $4.5 \mathrm{~g} / \mathrm{L}$ of lactic acid in the bulk solution.

\begin{tabular}{cccccc}
\hline Kinetics & Coefficients/Constants & Units & GAC & RLX425 & AMB400 \\
\hline \multirow{3}{*}{ Pseudo-Second Order } & $q_{e}$ & $\mathrm{mg} / \mathrm{g}$ & 38.2 & 17.2 & 31.2 \\
\cline { 2 - 6 } & $K_{2}$ & $\mathrm{mg} / \mathrm{g} / \mathrm{min}$ & 0.02 & 0.05 & 0.15 \\
\cline { 2 - 6 } & $h_{0}$ & $\mathrm{~min}^{-1}$ & 31.5 & 13.6 & 142.9 \\
\cline { 2 - 6 } & $R^{2}$ & - & 1 & 0.99 & 0.99 \\
\hline
\end{tabular}




\section{Discussion}

\subsection{Influence of Operating Parameters on the Adsorption of Lactic Acid onto GAC and Anionic Resins}

\subsubsection{Effect of $\mathrm{pH}$ and Adsorbent Dose on the Lactic Acid Adsorption Mechanisms}

The study shows that GAC, RLX425 and AMB400 can be used to adsorb lactic acid from a model fermentation broth used for T. neapolitana fermentation when it contains low concentration of lactic acid ( $<5 \mathrm{~g} / \mathrm{L})$. The adsorption capacity for GAC (38.2 $\mathrm{mg}$ lactic acid/g adsorbent) was found to be the highest, followed by AMB400 (31.2 mg lactic acid/g adsorbent) and RLX425 (17.2 mg lactic acid/g adsorbent) with $10 \%(w / v)$ adsorbent dose and an initial lactic acid concentration of $4.5 \mathrm{~g} / \mathrm{L}$ at $303.15 \mathrm{~K}$. This study also showed that the lactic acid recovery efficiency is better for the GAC and the AMB400 resin compared to the efficiencies reported by previous studies (Table 6).

Both GAC and the weakly basic anion exchange resin (RLX425) were effective in adsorbing lactic acid at a $\mathrm{pH}$ below the $p K_{a}$ (3.86) of lactic acid, whereas the strongly basic anion exchange resin (AMB400) was effective at a $\mathrm{pH}$ above the $p K_{a}$ (3.86) value (Figure 1b). The results show that GAC and RLX425 are effective at pH 2.0 and AMB400 is effective at pH 5.0 (Figure 1b). The adsorption of lactic acid onto GAC is due to a physical adsorption process and depends on electronic polarizability, the decreased physical adsorption of lactic acid at high pH (e.g., 5.0) is due to decreased dipole-dipole interactions [22].

Lactic acid is usually recovered from the fermentation broth via hydrophobic interactions with a neutral poly(styrene-co-DVB) resin at $\mathrm{pH}$ 2.0, as reported by Thang and Novalin [34]. In addition, Nielsen et al. [23] found that the adsorption of organic acids onto GAC or weakly basic anionic resins like Amberlite ${ }^{\circledR}$ IRA-67 is dominated at a $\mathrm{pH}$ below the $p K_{a}$ value of the acids, which was also observed for the RLX425 resin in this study (Figure 1b). RLX425 is a weakly-basic resin that has a pyridine functional group and the lone electron pair of the nitrogen atom allows it to form hydrogen bonds with the lactate ion [12]. Both GAC and the RLX425 resin are effective at a low pH (2.0), thus their use would require a post fermentation process with acidification of the medium below the standard $\mathrm{pH}$ value (4.5-6.5) that occurs during dark and capnophilic lactic fermentation [18,25]. On the other hand, a strongly basic adsorbent like AMB400, which is effective at pH 5.0, is more recommended for in situ extraction of lactic acid from a fermenter [20]. The results from this study were further validated by the observations from previous studies, where GAC as well as the weakly basic resins were effective in adsorbing lactic acid at a pH $2.0[16,18,22,25]$ and strongly basic resins were effective at a $\mathrm{pH} 5.0[20,35]$.

AMB400 is a strongly basic resin that has a quaternary ammonium as functional group with a positive charge and can thus form ionic bonds with the lactate ion. The binding of lactic acid to AMB400 predominantly occurs as: $\mathrm{R}_{\mathrm{rm}}{ }^{+} \mathrm{Cl}^{-}+\mathrm{L}^{-} \leftarrow \rightarrow \mathrm{R}_{\mathrm{rm}}{ }^{+} \mathrm{L}^{-}+\mathrm{Cl}^{-}$, where $L$ is the lactate ion and $\mathrm{R}_{\mathrm{rm}}$ is the resin matrix with a functional cationic group [36]. The $\mathrm{Cl}^{-}$form of the quaternary ammonium of the AMB400 resin has a weak basic property. This facilitates lactic acid adsorption through Lewis acid-base interactions with the partially positively-charged hydroxyl $\left(\mathrm{OH}^{-}\right)$and acidic protons $\left(\mathrm{H}^{+}\right)$of lactic acid [12,13]. The low recovery efficiency $(\sim 50 \%)$ of lactic acid with the AMB400 resin is attributed to the positively charged quaternary ammonium functional group which cannot be approached by the partially negatively-charged oxygen of the acid due to the steric hindrance provided by the bulk alkyl groups on the nitrogen as well as due to competing counter ion species (i.e., $\mathrm{Cl}^{-}$and $\mathrm{L}^{-}$) [13]. The lactic acid adsorption by the AMB400 resin occurs through an ion exchange mechanism [37].

The quaternary ammonium functional group can adsorb both molecular lactic acid and the lactate ion, however, further studies are required to demonstrate the competition between molecular lactic acid and the lactate ion. In addition, other organic components found in the real fermentation broth (e.g., acetic acid, alanine, glucose, tryptone, yeast extract etc.) are likely to impact the adsorption capacity and recovery efficiency due to composite uptake. The composite adsorption depends on the 
relative adsorption affinity, which is further linked to the polarity strength of the solute in the solution (e.g., acetic acid > ethanol > glycerol > glucose) [38].

Table 6. Lactic acid recovery from the model fermentation broths using GAC, RLX425 and AMB400 in batch adsorption experiments (adsorbent dose $10 \% \mathrm{w} / \mathrm{v}$ ).

\begin{tabular}{|c|c|c|c|c|c|c|}
\hline $\begin{array}{c}\text { Resin/ } \\
\text { Adsorbent }\end{array}$ & $\begin{array}{c}\text { Initial } \\
\mathrm{pH}\end{array}$ & $\begin{array}{c}\text { Temperature } \\
\text { (K) }\end{array}$ & $\begin{array}{l}\text { Initial Lactic Acid } \\
\text { Concentration } \\
(\mathrm{g} / \mathrm{L})\end{array}$ & $\begin{array}{c}q_{e}(\mathrm{mg} \text { Lactic } \\
\text { Acid/g } \\
\text { Adsorbent) }\end{array}$ & $E(\%)$ & References \\
\hline \multirow{5}{*}{ GAC } & 2 & 303.15 & 50 & 175 & 35 & [22] \\
\hline & 2 & 298.15 & 7 & 48 & 69 & [18] \\
\hline & 2 & 303.15 & 22 & 121 & 54 & This study \\
\hline & 2 & 303.15 & 4.8 & 38 & 81 & This study \\
\hline & 2 & 353.15 & 4.7 & 35 & 76 & This study \\
\hline \multirow{4}{*}{ RLX425 } & 2.83 & 303.15 & 5.7 & 32 & 56 & [16] \\
\hline & 2 & 303.15 & 22 & 60 & 27 & This study \\
\hline & 2 & 303.15 & 4.8 & 17 & 35 & This study \\
\hline & 2 & 353.15 & 4.7 & 9 & 18 & This study \\
\hline \multirow{7}{*}{ AMB400 } & 4 & 303.15 & 100 & 350 & 35 & [39] \\
\hline & 5 & 298.15 & 88.7 & 197 & 22 & [20] \\
\hline & 4.85 & 303.15 & 60 & 160 & 27 & [17] \\
\hline & 5 & 298.15 & 34 & 107 & 31 & [35] \\
\hline & 5 & 303.15 & 18 & 48 & 24 & This study \\
\hline & 5 & 303.15 & 5.4 & 31 & 57 & This study \\
\hline & 5 & 353.15 & 4.7 & 25 & 52 & This study \\
\hline
\end{tabular}

Notes: $q_{e}=$ amount of lactic acid adsorbed onto the adsorbent at equilibrium $(\mathrm{mg} / \mathrm{g})$ and $E=$ lactic acid recovery efficiency (\%).

In addition to $\mathrm{pH}$, the adsorbent dose (Figure 1c) plays a major role in the absorption of lactic or organic acids. In this study, the increased adsorbent dose from $5 \%$ to $30 \%(w / v)$ has increased the lactic acid recovery efficiency by $10 \%$ for GAC and by $50 \%$ for both RLX 425 and AMB400 resins (Figure 1c). However, an adsorbent dose of $10 \%(w / v)$ was found to be suitable for all the adsorbents at $303.15 \mathrm{~K}$ with an initial lactic acid concentration of $4.5 \mathrm{~g} / \mathrm{L}$ (Figure 1c) as also reported by other authors [18,22,25]. Yousuf et al. [18] studied the effect of adsorbent (Amberlite ${ }^{\circledR}$ IRA-67 and activated carbon) dose $(2-20 \%, w / v)$ on the lactic acid recovery efficiency and found that $10 \%(w / v)$ was the most appropriate adsorbent dose at $298.15 \mathrm{~K}$ with an initial lactic acid concentration ranging between 6.7 and $7.0 \mathrm{~g} / \mathrm{L}$. Gao et al. [25] also studied the effect of the adsorbent (Amberlite ${ }^{\circledR}$ IRA-67) dose (5-17.5\%) on the lactic acid recovery efficiency and reported that $10 \%(w / v)$ is the best performing adsorbent dose for initial lactic acid concentrations varying between 21.0 and $99.5 \mathrm{~g} / \mathrm{L}$, at $323.15 \mathrm{~K}$. In contrast, Gao et al. [22] found that a 30\% $(w / v)$ activated carbon dose was suitable for lactic acid recovery from an initial lactic acid concentration of $50.0 \mathrm{~g} / \mathrm{L}$ at $303.15 \mathrm{~K}$ when tested on adsorbent doses ranging between $10 \%$ and $50 \%(w / v)$.

\subsubsection{Effect of Temperature on Lactic Acid Adsorption}

The effect of temperature ( 303.15 to $353.15 \mathrm{~K}$ ) shows an interesting trend for lactic acid adsorption from the model fermentation broth (Figure 2a). Increasing the temperature from 303.15 to $353.15 \mathrm{~K}$ decreased the adsorption capacity of GAC and RLX 425 by $~ 13 \%$ and $~ 50 \%$, respectively. Among the adsorbents tested in this study, the AMB400 resin was the most efficient adsorbent for lactic acid recovery, because of its operational flexibility at varying temperature ranges. Gao et al. [25] reported that the lactic acid adsorption capacity decreased by $\sim 20 \%$ for the Amberlite ${ }^{\circledR}$ IRA- 67 resin when the temperature increased from 293.15 to $323.15 \mathrm{~K}$ with an initial lactic acid concentration of $42.5 \mathrm{~g} / \mathrm{L}$. In another study, the adsorption capacity of the lactic acid onto zeolite molecular sieves decreased from $10.5 \mathrm{mg} / \mathrm{g}$ to $3.6 \mathrm{mg} / \mathrm{g}$ when the temperature increased from $299.15 \mathrm{~K}$ to $339.15 \mathrm{~K}$ with an initial lactic acid concentration varying between 14.2 and $16.1 \mathrm{~g} / \mathrm{L}$ [40]. The decrease in lactic acid adsorption at higher temperatures is mainly due to weak interactions between the active sites of the adsorbent 
and adsorbate molecules [41]. The extraction of acids by GAC and amine groups is shown to be exothermic and decreases with increase in temperature due to the following reasons: (i) decrease in the adsorption affinity towards adsorbate molecules; (ii) shifting the equilibrium towards the liquid phase; and (iii) promoting desorption as the reactions are exothermic in nature [42].

\subsection{Thermodynamics Analysis of Lactic Acid Adsorption}

The negative values of $\Delta G^{0}(-9.9$ to $-10.9 \mathrm{~kJ} / \mathrm{mol})$ and $\Delta H^{0}(-16.7 \mathrm{~kJ} / \mathrm{mol})$ revealed that the lactic acid adsorption onto GAC was spontaneous and exothermic between $303.15 \mathrm{~K}$ and $353.15 \mathrm{~K}$ (Table 3). Similarly, the negative values of $\Delta G^{0}(-4.5$ to $-1.9 \mathrm{~kJ} / \mathrm{mol})$ and $\Delta H^{0}(-19.9 \mathrm{~kJ} / \mathrm{mol})$ assures that the lactic acid adsorption onto the RLX425 resin was spontaneous and exothermic between 303.15 and $353.15 \mathrm{~K}$ (Table 3). On the contrary, the negative values of $\Delta G^{0}(-5.5$ to $-6.8 \mathrm{~kJ} / \mathrm{mol})$ and positive values for $\Delta H^{0}(+2.0 \mathrm{~kJ} / \mathrm{mol})$ showed that the lactic acid adsorption onto the AMB400 resin was spontaneous, but endothermic between $303.15 \mathrm{~K}$ and $353.15 \mathrm{~K}$ due to ion exchange mechanisms (Table 3). Gao et al. [25] calculated the thermodynamic parameters for the lactic acid adsorption onto a weakly basic anionic (Amberlite ${ }^{\circledR}$ IRA-67) resin between $293.15 \mathrm{~K}$ and $323.15 \mathrm{~K}$. In that study, the $\Delta H^{0}$ value for lactic acid adsorption onto Amberlite ${ }^{\circledR}$ IRA- 67 was $-32.8 \mathrm{~kJ} / \mathrm{mol}$ and the adsorption process was exothermic between $298.15 \mathrm{~K}$ and $323.15 \mathrm{~K}$. Aljundi et al. [40] reported that the $\Delta H^{0}$ value for the lactic acid adsorption onto zeolite molecular sieves was $+29( \pm 17) \mathrm{kJ} / \mathrm{mol}$ and the adsorption process was endothermic between $299.15 \mathrm{~K}$ and $339.15 \mathrm{~K}$.

The negative values of $\Delta G^{0}$ descending with the increase of temperature indicated a decrease in lactic acid adsorption from the bulk solution at elevated temperatures ( $>313.15 \mathrm{~K})$ for both GAC and RLX425. On the other hand, the negative values of $\Delta G^{0}$ ascending with temperature increase indicated a slight increase in lactic acid adsorption with the AMB400 resin (Table 3). The study by Gao et al. [25] showed that the $\Delta G^{0}(-8.8$ to $-6.7 \mathrm{~kJ} / \mathrm{mol})$ decreased with an increase in the temperature between 298.15 and $323.15 \mathrm{~K}$ for lactic acid adsorption onto the Amberlite ${ }^{\circledR}$ IRA-67 resin.

The negative $\Delta S^{0}$ value $(-0.05 \mathrm{~kJ} /(\mathrm{mol} \mathrm{K}))$ for the weakly-basic resin (RLX425) shows decreased randomness at the adsorbent-adsorbate interface during the adsorption of lactic acid onto the active sites of the resin, which was further validated by the negative $\Delta S^{0}(-0.8 \mathrm{~kJ} /(\mathrm{mol} \mathrm{K}))$ value found in a previous study on a weakly-basic resin (Amberlite ${ }^{\circledR}$ IRA-67) [25]. In addition, the positive value of $\Delta S^{0}(0.02 \mathrm{~kJ} /(\mathrm{mol} \mathrm{K}))$ indicates the increased randomness at the adsorbent-adsorbate interface during the adsorption of lactic acid onto the active sites of the AMB400 resin. From the adsorption results at varying temperature, the increase in temperature decreased the recovery efficiency for both GAC and RLX425 (Figure 2a), which was further validated by the $\Delta G^{0}$ values in Table 3 as the reaction spontaneity was found to decrease with an increase in the temperature [26].

Generally, the adsorption enthalpy for physical adsorption (or electrostatic interaction between adsorption sites and the adsorbate species) ranges between -20 and $40 \mathrm{~kJ} / \mathrm{mol} \mathrm{[43]}$ and for chemisorption between -80 and $-400 \mathrm{~kJ} / \mathrm{mol}$, respectively [25,44]. The $\Delta H^{0}(-16.7 \mathrm{~kJ} / \mathrm{mol}$ for GAC and $-19.9 \mathrm{~kJ} / \mathrm{mol}$ for RLX425) values obtained in this study were within the range of physical adsorption. Hence, the adsorption experiments with GAC and anionic resins indicated a physical adsorption process for lactic acid adsorption. In a related study, adsorption of acetic, propionic and butyric acid onto activated carbon and a weak base anionic resin (Puralite A133S) showed a physical adsorption (i.e., $\Delta H^{0}$ between -20 and $40 \mathrm{~kJ} / \mathrm{mol}$ ) process based on the thermodynamic analysis and the favorability: butyric $>$ acetic $>$ propionic acid [45]. The amount of lactic acid adsorbed via ion exchange (AMB400) was slightly lower than that adsorbed by physical adsorption (GAC and RLX425) [37].

\subsection{Lactic Acid Adsorption Isotherms}

Among the isotherms investigated, the Langmuir isotherm was found to be more suitable in explaining the adsorption mechanism compared to the Freundlich and Temkin isotherms. The Dubinin-Radushkevich isotherm and intraparticle diffusion kinetic model were investigated 
in this study for lactic acid adsorption, but none of these two models were able to explain the experimental results of lactic acid adsorption (data not shown). The understanding of the lactic acid adsorption mechanism can be improved by applying the Redlich-Peterson isotherm (a hybrid isotherm featuring both Langmuir and Freundlich) and a multilayer adsorbent-adsorbate interface Brunauer-Emmett-Teller (BET) isotherm model to fixed bed column experiments [29].

In a similar study, adsorption of formic acid onto Amberlite ${ }^{\circledR}$ IRA-67 followed the Langmuir isotherm under similar operating conditions [32]. In contrast, Gao et al. [25] showed that the lactic acid adsorption onto Amberlite ${ }^{\circledR}$ IRA-67 was fitted by the Freundlich isotherm model. The plot (Figure 3a) from the Langmuir isotherm shows that the lactic acid was adsorbed as a monolayer and homogeneously distributed over the surface of the adsorbent with restricted interaction between the adsorbate (i.e., lactic acid) molecules (Table 4). In addition, the Langmuir isotherm also suggests that adsorption of lactic acid onto the GAC, RLX425 and AMB400 is favorable $\left(0<R_{L}<1\right)$.

\subsection{Prospectives of Lactic Acid Adsorption}

The strongly basic resin AMB400 showed a higher lactic acid removal efficiency and capacity compared to GAC and RLX425 at a pH above the $p K_{a}$ value of the lactic acid (3.86) that is suitable for most of the fermentation processes to recover lactic acid. The thermodynamic analyses shows a stable lactic acid adsorption in the range of 303.15-353.15 K for AMB400 compared to GAC and RLX425. So, this enables AMB400 resin to recover lactic acid on a wide range of operating temperatures. In addition, the effects of competitive adsorption of the lactic acid need to be assessed in the presence of other constituents present in a fermentation broth, such as sugars, organic acids, salts and amino acids.

The current study shows that the strongly basic resin AMB400 is a better adsorbent than GAC and the weakly basic resin RLX425 for a model fermentation broth containing only lactic acid. However, the amount of the lactic acid adsorbed to the adsorbents cannot be used as a sole parameter to choose an appropriate adsorbent [18]. In addition, the adsorption capacity of the resins can decrease after various cycles of adsorption and desorption and thus long term performance of the resins is vital to select the most economical and feasible resin [18]. Desorption of lactic acid from the adsorbents is an important factor that needs to be examined as a downstream processing strategy, but was beyond the scope of this study. According to previous studies, the adsorbed lactic acid onto GAC and anionic resins can be desorbed by various chemicals, depending on the $\mathrm{pH}$, temperature and functional groups present on the adsorbents as well as the nature of the desorbent, i.e., acetone, methanol, $1 \mathrm{M} \mathrm{NaCl}$, $\mathrm{NaOH}(2-4 \%), \mathrm{NH}_{4} \mathrm{OH}(2-4 \%), \mathrm{Na}_{2} \mathrm{CO}_{3}(4-8 \%)$ or $1 \mathrm{M} \mathrm{H}_{2} \mathrm{SO}_{4}[13,22,25]$.

In addition to desorption studies, it is important to scale-up the batch experiments with fixed-bed adsorption columns along with analysis of the lactic acid adsorption breakthrough curves in order to evaluate the most economical and feasible adsorbents for the lactic acid removal from the fermentation broths. The optical purity of the lactic acid can be achieved $>99 \%$ by desorbing it with organic solvents (e.g., acetone and methanol) [22]. The optical purity of the lactic acid will slightly decrease when it is desorbed with $\mathrm{HCl}, \mathrm{NaOH}$ and $\mathrm{NaCl}$. In addition, the optical purity of the acid will be impacted by the presence of other constituents in the model or real fermentation broth. The contamination can be reduced by filtration or acid/base treatments. Accordingly, further investigations can optimize integrated or even in situ recovery of organic acids from a real fermentation broth used for T. neapolitana fermentation.

\section{Conclusions}

GAC as well as weak and strong base anion exchange resins were successfully applied for the separation of lactic acid from a model fermentation broth at a $\mathrm{pH}$ above and below the $p K_{a}(3.86)$ value of lactic acid. The temperature experiments showed that increasing the temperature from 303.15 to $353.15 \mathrm{~K}$ decreased the lactic acid recovery efficiency by $50 \%$ and $13 \%$ for RLX425 resin and GAC, respectively, whereas the recovery efficiency remained unchanged for the AMB400 resin. From the thermodynamic analysis, the lactic acid adsorption onto the adsorbents suggests a physical adsorption 
mechanism for both GAC and RLX 425 and ion exchange for the AMB400 resin. The equilibrium adsorption data for the lactic acid were adequately explained by the Langmuir isotherm model, indicating a monolayer adsorption process. Lactic acid recovery was found to be well represented by pseudo-second order kinetics. Among the different adsorbents tested, the strongly basic resin (AMB400) showed good lactic acid recovery from the model fermentation broth in terms of adsorption kinetics, adsorption capacity and thermodynamic feasibility.

Acknowledgments: This work was funded by the Erasmus Mundus Joint Doctorate program $\mathrm{ETeCoS}^{3}$ (Environmental Technologies for Contaminated Solids, Soils and Sediments) under the EU grant agreement FPA No. 2010-0009. This work was further supported by the Italian Ministry of Education, University and Research (MIUR) through the project "Sfruttamento Integrato di Biomasse Algali in Filiera Energetica di Qualità (SIBAFEQ)" (PON01_02740) and by the CNR through the project "Energia da FOnti Rinnovabili (EFOR)". The authors would like to thank the laboratory staff of UNESCO-IHE for their analytical support.

Author Contributions: Nirakar Pradhan carried out the experiments and bibliographic search; Nirakar Pradhan, Eldon R. Rene, and Piet N. L. Lens performed the data analysis and wrote the manuscript; Eldon R. Rene, Piet N. L. Lens, Laura Dipasquale, Giuliana d'Ippolito, Angelo Fontana, Antonio Panico, and Giovanni Esposito corrected the manuscript and improved the discussion.

Conflicts of Interest: The authors declare no conflict of interest.

\section{References}

1. Hamad, K.; Kaseem, M.; Deri, F. Melt rheology of poly(lactic acid)/low density polyethylene polymer blends. Adv. Chem. Eng. Sci. 2011, 1, 208-214. [CrossRef]

2. Hamad, K.; Kaseem, M.; Deri, F. Rheological and mechanical properties of poly(lactic acid)/polystyrene polymer blend. Polym. Bull. 2010, 65, 509-519. [CrossRef]

3. Bayazit, S.S.; Inci, I.; Uslu, H. Adsorption of lactic acid from model fermentation broth onto activated carbon and Amberlite IRA-67. J. Chem. Eng. Data 2011, 56, 1751-1754. [CrossRef]

4. Joglekar, H.G.; Rahman, I.; Babu, S.; Kulkarni, B.D.; Joshi, A. Comparative assessment of downstream processing options for lactic acid. Sep. Purif. Technol. 2006, 52, 1-17. [CrossRef]

5. Martinez, F.A.C.; Balciunas, E.M.; Salgado, J.M.; Gonzalez, J.M.D.; Converti, A.; Oliveira, R.P.S. Lactic acid properties, applications and production: A review. Trends Food Sci. Technol. 2013, 30, 70-83. [CrossRef]

6. Dipasquale, L.; D'Ippolito, G.; Fontana, A. Capnophilic lactic fermentation and hydrogen synthesis by Thermotoga neapolitana: An unexpected deviation from the dark fermentation model. Int. J. Hydrogen Energy 2014, 39, 4857-4862. [CrossRef]

7. Pradhan, N.; Dipasquale, L.; D’Ippolito, G.; Fontana, A.; Panico, A.; Pirozzi, F.; Lens, P.N.L.; Esposito, G. Model development and experimental validation of capnophilic lactic fermentation and hydrogen synthesis by Thermotoga neapolitana. Water Res. 2016, 99, 225-234. [CrossRef] [PubMed]

8. Pradhan, N.; Dipasquale, L.; D’Ippolito, G.; Fontana, A.; Panico, A.; Lens, P.N.L.; Pirozzi, F.; Esposito, G. Kinetic modeling of fermentative hydrogen production by Thermotoga neapolitana. Int. J. Hydrogen Energy 2016, 41, 4931-4940. [CrossRef]

9. Pradhan, N.; Dipasquale, L.; D’Ippolito, G.; Panico, A.; Lens, P.N.L.; Esposito, G.; Fontana, A. Hydrogen production by the thermophilic bacterium Thermotoga neapolitana. Int. J. Mol. Sci. 2015, 16, 12578-12600. [CrossRef] [PubMed]

10. Bernardo, M.P.; Coelho, L.F.; Sass, D.C.; Contiero, J. L-(+)Lactic acid production by Lactobacillus rhamnosus B103 from dairy industry waste. Braz. J. Microbiol. 2016, 47, 640-646. [CrossRef] [PubMed]

11. Sugiyama, M.; Akase, S.; Nakanishi, R.; Kaneko, Y.; Harashima, S. Overexpression of ESBP6 improves lactic acid resistance and production in Saccharomyces cerevisiae. J. Biosci. Bioeng. 2016, 122, 415-420. [CrossRef] [PubMed]

12. Wasewar, K.L. Separation of lactic acid: Recent advances. Chem. Biochem. Eng. Q. 2005, 19, 159-172.

13. Dethe, M.J.; Marathe, K.V.; Gaikar, V.G. Adsorption of lactic acid on weak base polymeric resins. Sep. Sci. Technol. 2006, 41, 2947-2971. [CrossRef]

14. Yi, S.S.; Lu, Y.C.; Luo, G.S. Separation and concentration of lactic acid by electro-electrodialysis. Sep. Purif. Technol. 2008, 60, 308-314. [CrossRef] 
15. Takatsuji, W.; Nakauchi, M.; Yoshida, H. Removal of salt and organic acids from solution used to season salted Japanese apricots (ume) by electrodialysis, precipitation and adsorption. J. Biosci. Bioeng. 1999, 88, 348-351. [CrossRef]

16. Evangelista, R.L.; Mangold, A.J.; Nikolov, Z.L. Recovery of lactic acid by sorption: Resin evaluation. Appl. Biochem. Biotechnol. 1994, 45-46, 131-144. [CrossRef]

17. Moldes, A.B.; Alonso, J.L.; Parajo, J.C. Recovery of lactic acid from simultaneous saccharification and fermentation media using anion exchange resins. Bioprocess Biosyst. Eng. 2003, 25, 357-363. [CrossRef] [PubMed]

18. Yousuf, A.; Bonk, F.; Oyanedel, J.R.B.; Schmidt, J.E. Recovery of carboxylic acids produced during dark fermentation of food waste by adsorption on Amberlite IRA-67 and activated carbon. Bioresour. Technol. 2016, 217, 137-140. [CrossRef] [PubMed]

19. Tong, W.Y.; Fu, X.Y.; Lee, S.M.; Yu, J.; Liu, J.W.; Wei, D.W.; Koo, Y.M. Purification of L-(+)lactic acid from fermentation broth with paper sludge as a cellulosic feedstock using weak anion exchanger Amberlite IRA-92. Biochem. Eng. J. 2004, 18, 89-96. [CrossRef]

20. Cao, X.; Yun, H.S.; Koo, Y.M. Recovery of L-(+)lactic acid by anion exchange resin Amberlite IRA-400. Biochem. Eng. J. 2002, 11, 189-196. [CrossRef]

21. Antonio, G.R.; Vaccari, G.; Dosi, E.; Trilli, A.; Rossi, M.; Matteuzzi, D. Enhanced production of L-(+)lactic acid in chemostat by Lactobacillus casei DSM 20011 using ion-exchange resins and cross-flow filtration in a fully automated pilot plant controlled via NIR. Biotechnol. Bioeng. 2000, 67, 147-156.

22. Gao, M.T.; Shimamura, T.; Ishida, N.; Takahashi, H. pH-uncontrolled lactic acid fermentation with activated carbon as an adsorbent. Enzym. Microb. Technol. 2011, 48, 526-530. [CrossRef] [PubMed]

23. Nielsen, D.R.; Amarasiriwardena, G.S.; Prather, K.L.J. Predicting the adsorption of second generation biofuels by polymeric resins with applications for in situ product recovery (ISPR). Bioresour. Technol. 2010, 101, 2762-2769. [CrossRef] [PubMed]

24. Park, K.M.; Nam, H.G.; Lee, K.B.; Mun, S. Adsorption behaviors of sugars and sulfuric acid on activated porous carbon. J. Ind. Eng. Chem. 2016, 34, 21-26. [CrossRef]

25. Gao, Q.; Liu, F.; Zhang, T.; Zhang, J.; Jia, S.; Yu, C.; Jiang, K.; Gao, N. The role of lactic acid adsorption by ion exchange chromatography. PLoS ONE 2010, 5, e13948. [CrossRef] [PubMed]

26. Zhou, Q.; Chen, F.; Wu, W.; Bu, R.; Li, W.; Yang, F. Reactive orange 5 removal from aqueous solution using hydroxyl ammonium ionic liquids/layered double hydroxides intercalation composites. Chem. Eng. J. 2016, 285, 198-206. [CrossRef]

27. Rich, W.; Johnson, E.; Lois, L.; Kabra, P.; Stafford, B.; Marton, L. Determination of organic acids in biological fluids by ion chromatography: Plasma lactate and pyruvate and urinary vanillylmandelic acid. Clin. Chem. 1980, 26, 1492-1498. [PubMed]

28. Pezoti, O.; Cazetta, A.L.; Bedin, K.C.; Souza, L.S.; Martins, A.C.; Silva, T.L.; Junior, O.O.S.; Visentainer, J.V.; Almeida, V.C. NaOH-activated carbon of high surface area produced from guava seeds as a high-efficiency adsorbent for amoxicillin removal: Kinetic, isotherm and thermodynamic studies. Chem. Eng. J. 2016, 288, 778-788. [CrossRef]

29. Foo, K.Y.; Hameed, B.H. Insights into the modeling of adsorption isotherm systems. Chem. Eng. J. 2010, 156, 2-10. [CrossRef]

30. Webber, T.W.; Chakkravorti, R.K. Pore and solid diffusion models for fixed-bed adsorbers. AIChE J. 1974, 20, 228-238. [CrossRef]

31. Chen, X. Modeling of experimental adsorption isotherm data. Information 2015, 6, 14-22. [CrossRef]

32. Uslu, H. Adsorption equilibria of formic acid by weakly basic adsorbent Amberlite IRA-67: Equilibrium, kinetics, thermodynamic. Chem. Eng. J. 2009, 155, 320-325. [CrossRef]

33. Shi, Y.; Kong, X.; Zhang, C.; Chen, Y.; Hua, Y. Adsorption of soy isoflavones by activated carbon: Kinetics, thermodynamics and influence of soy oligosaccharides. Chem. Eng. J. 2013, 215-216, 113-121. [CrossRef]

34. Thang, V.H.; Novalin, S. Green biorefinery: Separation of lactic acid from grass silage juice by chromatography using neutral polymeric resin. Bioresour. Technol. 2008, 99, 4368-4379. [CrossRef] [PubMed]

35. Quintero, J.; Acosta, A.; Mej1a, C.; Rios, R.; Torres, M. Purification of lactic acid obtained from a fermentative process of cassava syrup using ion exchange resins. Rev. Fac. Ing.-Univ. Antioq. 2016, 65, 139-151.

36. Bishai, M.; De, S.; Adhikari, B.; Banerjee, R. A platform technology of recovery of lactic acid from a fermentation broth of novel substrate Zizyphus oenophlia. 3 Biotech 2015, 5, 455-463. [CrossRef] [PubMed] 
37. Sodsai, W.; Sookkumnerd, T. Modeling of lactic acid adsorption isotherm by anion exchange resin Amberlite IRA-96. KMITL Sci. Technol. J. 2013, 13, 82-86.

38. Zhou, J.; Wu, J.; Liu, Y.; Zou, F.; Wu, J.; Li, K.; Chen, Y. Modeling of breakthrough curves of single and quaternary mixtures of ethanol, glucose, glycerol and acetic acid adsorption onto a microporous hyper-cross-linked resin. Bioresour. Technol. 2013, 143, 360-368. [CrossRef] [PubMed]

39. Rampai, T.; Thitiprasert, S.; Boonkong, W.; Kodama, K.; Tolieng, V.; Thongchul, N. Improved lactic acid productivity by simultaneous recovery during fermentation using resin exchanger. Asia-Pac. J. Sci. Technol. 2016, 21, 193-199.

40. Aljundi, I.H.; Belovich, J.M.; Talu, O. Adsorption of lactic acid from fermentation broth and aqueous solutions on zeolite molecular sieves. Chem. Eng. Sci. 2005, 60, 5004-5009. [CrossRef]

41. Ye, C.; Wang, X.; Wang, H.; Wang, Z. Effects of counter anions on the adsorption properties of 4-methylimidazolium-modified silica materials. J. Taiwan Inst. Chem. Eng. 2014, 45, 2868-2877. [CrossRef]

42. Farhadpour, F.A.; Bono, A. Sorptive separation of ethanol-water mixtures with a bi- dispersed hydrophobic molecular sieve, silicalite: Determination of the controlling mass transfer mechanism. Chem. Eng. Process. 1996, 35, 141-155. [CrossRef]

43. Lian, L.; Guo, L.; Guo, C. Adsorption of Congo red from aqueous solutions onto Ca-bentonite. J. Hazard. Mater. 2009, 161, 126-131. [CrossRef] [PubMed]

44. Kolodynska, D. Adsorption characteristics of chitosan modified by chelating agents of a new generation. Chem. Eng. J. 2012, 179, 33-43. [CrossRef]

45. Da Silva, A.H.; Miranda, A.E. Adsorption/desorption of organic acids onto different adsorbents for their recovery from fermentation broths. J. Chem. Eng. Data 2013, 58, 1454-1463. [CrossRef]

(C) 2017 by the authors. Licensee MDPI, Basel, Switzerland. This article is an open access article distributed under the terms and conditions of the Creative Commons Attribution (CC BY) license (http:/ / creativecommons.org/licenses/by/4.0/). 